\title{
A search for homologues of plant photoreceptor genes and their signaling partners in the sugarcane expressed sequence tag (Sucest) database
}

\author{
Roberto V. Santelli* and Fábio Siviero
}

\begin{abstract}
A search in the sugarcane expressed sequence tag (SUCEST) database for homologues of plant genes involved in photo-sensory mechanisms was carried out using the basic local alignment tool (BLAST). Our results shown that known elements (phytochromes, cryptochromes and phototoprin) present in Arabidopsis and other higher plants were detected with low e-values. We also searched for proteins interacting with photoreceptors in primary or downstream signaling events. One putative homologue for a protein postulated to be a primary element in phytochrome signaling pathways was identified, as were other candidates for downstream interacting factors.
\end{abstract}

\section{INTRODUCTION}

Extensive reviews are available focusing on all aspects of photoreception in plants (Nagy et al., 2000; Quail, 2000; Hudson, 2000). However as the field is broad, we will present basic information for a better evaluation of our results.

The molecules engaged in the perception of light are specialized ones and are classified based upon the quality of the light absorb, i.e. phytochromes absorb in the red and far-red, and the cryptochromes and phototropin absorb UV-A and blue light.

In Arabidopsis the photoreceptors are present as two groups: the first group being the phytochrome gene family, which has five members (phytochromes A, B, C, D and E) and the other group consisting of two cryptochromes (cry1 and cry2) and one phototropin (nph1).

Phytochromes are photochromic pigments that exert their regulatory activity by switching between two forms: an active Pfr form by absorbing red light and an inactive $\mathrm{Pr}$ form by absorbing far-red light (Figure 1). Phytochromes are localized in the cytosol in both etiolated seedlings and in plants adapted to growth in the dark. Subsequent nuclear residence of phytochromes depends on quality and quantity of light (Nagy et al., 2000; Nagy et al., 2001).

Three groups of researchers, utilizing the yeast two-hybrid system, were able to locate candidates for primary phytochrome action.

One primary phytochrome action candidate is phytochrome Interacting Factor 3 (PIF3) which was isolated by Peter Quail's group using as bait the portion of phytochrome $\mathrm{B} \mathrm{COOH}$-terminal domain which is not involved in chromophore binding response. Interestingly the re-conversion of phyB to its non-reactive form caused dissociation of PIF3. This result was the first in vitro demonstration of a photo-reversible binding between a phytochrome and its putative signaling partner (Ni et al., 1999). According to Zhu et al. (2000) the apparent affinity of PIF3 is higher for phyB than for phytocheome A (phyA) PIF3 has a bipartite signature with a nucleus localization signal (NLS) and a basic helix-loop-lelix (bHLH) motif of this super-family of transcription factors, common in the Arabidopsis genome. The target DNA is a palindrome, CACGTG, of the G-box sequence motif, present in various light-regulated gene promoters (Martinez-Garcia, 2000). The nuclear localization of PIF3 and its binding properties indicate that after translocation to the nucleus the photoactive form of phyA or/and B, interacts with PIF3; this being a primary stage in light-induction gene activation. The overall situation is thus a positive regulation of phytochrome action.

A second primary phytochrome action candidate was isolated using the $\mathrm{C}$ terminal domain of PHYA as bait by Joanne Chory's group who isolated a protein with different properties, phytochrome kinase substrate 1 (PKS1) (Fankhauser et al., 1999) present in the cytoplasm. The $\mathrm{N}$-terminal of this protein can be phosphorylated on its serine and threonine residues by preparations of recombinant oat phyA extracted from yeast, in Pr and Pfr conditions, but not with the protein obtained from dark grown controls. It thus appears that phyA function as a protein-kinase. This data supports the proposition that PKS1 is a candidate for a primary partner in phytochrome signal transduction initiation. A scheme for the putative interactions of phytochromes, PKS1 and PIF3 is shown in Figure 1

The third possible primary phytochrome action candidate, isolated by Choi et al. (1999) is nucleoside diphosphate kinase 2 (NDPK2). However NDKP2 is known to participate in several other developmental processes in 


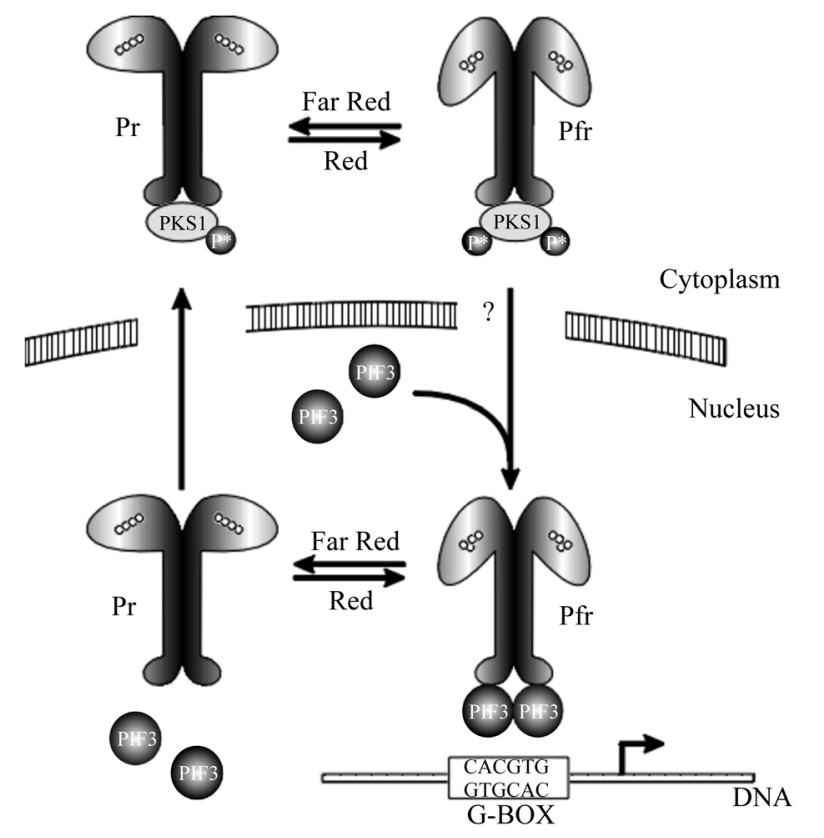

Figure 1 - The scheme (modified from Smith, 1999) is based on the data from Quail's and Chory's groups on PIF3 and PKS1. Phytochromes are represented by their dimeric form. They oscillate between an inactive state (Pr) and an activated (Pfr) form, under far-red or red light, respectively. The mechanism which govern the nucleo-cytoplasmic partitioning of phytochromes are of limited information in higher plants. PKS1 has two possible levels of phosphorylation and may act as a docking protein in the less phosphorylated state. The possibility of PIF3 associating with other transcription factors that also recognize the $\mathrm{G}$ box motif has been suggested. The symbol oooo represents tetra-pyrrol - P phosphorylated residue in PKS1 (see text).

other organisms and the present data in plants is far from conclusive.

Several other transcription factors are shown to act downstream in photoreceptor transduction pathways, e.g. the bZIP (basic Zipper) circadian clock associated 1 (CCA1) (Wang et al. 1998), the nuclear protein GI (GIGANTEA) (Huq et al., 2000), the bHLH protein, long hypocotyl in far-red (HFR1) (which binds PIF3 by a possible mechanism of in vivo heterodimerization (Fairchild et al., 2000) and COP1 (constitutive photomorphogenic 1), a negative regulator of CRY1 (McNellis et al. 1994) (Yang et al., 2001).

Three blue light photoreceptors, cryptochrome1 (cry1), cryptochrome 2 (cry2) and phototropin (nph1) were identified in Arabidopsis. The main regulatory events for this class of photoreceptors are, hypocotyl inhibition, flowering time and phototropism, while other functions include stimulation of cotyledon expansion and circadian changes in response to light.

Phototropism appears to be exclusive of nph1 regulation (Christie et al., 1998; Liscum and Stowe-Evans, 2000) but the possibility is not excluded of other photoreceptors acting in the range of high intensity blue light. Recently it has been observed in Arabidopsis that a NPH1 homologue, the protein NPL1 seems to be functionally linked to the chloroplast high-light avoidance response (Kagawa et al., 2001; Jarillo et al., 2001). Unlike the position with phyA and phyB, little is known for downstream regulation for the blue receptors. In the case of phototropin (nph1), a candidate protein NPH3 (Moutchoulski and Liscum, 1999), with potential protein-protein interaction motifs was isolated and characterized by Moutchoulski and Liscum (1999).

Finally, although being proteins which reside in the nucleus (or are nuclear bound), interactions (cross-talk), collectively referred to as co-action, between phytochromes and cryptochromes, has been suggested by Guo et al. (2001), as is the case for the $\mathrm{Ca}^{2+}$ binding protein SUB1.

\section{MATERIAL AND METHODS}

All sequences analyzed were from the SUCEST database. Descriptions of the libraries that generated the Ests clones as well as protocols for sequencing and the general strategies used in the SUCEST project can be found at http://sucest.lbi.dcc.unicamp.br. Sequence analysis was performed using the BLAST facility and the 'search by keyword' service, both available on the SUCEST site, and the clustalX 1.8 program (Thompson et al., 1997) on a workstation running under Linux (Debian 3.0) with the ToolKit 6.1 (NCBI), Vibrant 6.1 (NCBI) packages installed.

The BLAST program used was tblastn, using as query sequences proteins mainly from Arabidopsis thaliana and Oryza sativa genomes. The search by keyword service on the SUCEST site uses as database the Blastx and Blastn of the SUCEST sequences in NCBI Blast site response. The results were filtered restricting the hits to an E value 1E-15. The phylogenetic dendrogram was constructed using ClustalX 1.8.

\section{RESULTS}

Our search for homologues of genes involved in photoreception was focused on three main groups: 1) phytochromes, 2) cryptochromes and phototropin and 3) primary targets and downstream putative regulators. The Table1 is constructed in relation to the best score and lowest e-value.

\section{PHYLOGENETIC RELATIONSHIPS}

The grass family (POACEAE) has recently been submitted to extensive phylogenetic analysis of phytochrome B $(P H Y B)$ nuclear DNA sequences using a 1.2 kilobase $(\mathrm{kb})$ region of the $P H Y B$ gene first exon that encompasses the chromophore binding site (Mathews et al., 2000). Unfortunately, the complete sequence of this gene is not in the Sucest database. Nevertheless we applied the clustralX alignment program using the existent sugarcane $P H Y B$ sequence, against several complete sequences from current databases. The results are presented in the dendrogram (Figure 2). 
Table I - Results of a Basic local alignment search tool (Blast) for groups of genes involved in photoreception. The sugarcane expressed sequence tag (Sucest) was used for the search. Clusters were made with the sugarcane expressed sequence tag (SUCEST) database and using the CAP3 (Contig Assembly Program, version 3).

\begin{tabular}{|c|c|c|c|c|}
\hline Query sequence & Accenssion number & Sugarcane cluster & Score & E-Value \\
\hline \multicolumn{5}{|l|}{ Phytochrome A } \\
\hline Sorghum bicolor & GI11134026 & SCCCCL3080H06.g & 1439 & 0.0 \\
\hline Zea mays & GI130186 & SCAGAM2017G02.g & 325 & $2 \mathrm{E}-88$ \\
\hline \multicolumn{5}{|l|}{ Phytochrome B } \\
\hline Sorghum bicolor & GI11134029 & SCQSLR1040D12.g & 708 & 0.0 \\
\hline \multicolumn{5}{|l|}{ Phytochrome C } \\
\hline Sorghum bicolor & GI11134032 & SCCCLR1065C10.g & 903 & 0.0 \\
\hline \multicolumn{5}{|l|}{ Cryptocrome 1} \\
\hline \multirow[t]{3}{*}{ Oryza sativa } & & SCAGST3138B05.g & 421 & $1 \mathrm{E}-117$ \\
\hline & GI16444957 & SCJLHR1027C08.g & 544 & $1 \mathrm{E}-154$ \\
\hline & & SCBFRZ3009A01.g & 308 & $2 \mathrm{E}-83$ \\
\hline \multicolumn{5}{|l|}{ Cryptochrome 2} \\
\hline Lycopersicon esculentum & GI8101444 & SCRFST1042F05.g & 270 & $2 \mathrm{E}-71$ \\
\hline \multicolumn{5}{|l|}{ Phototropin } \\
\hline Zea mays & GI2687358 & SCCCRZ3001D06.g & 1009 & 0.0 \\
\hline \multicolumn{5}{|l|}{ PIF3 } \\
\hline \multirow[t]{2}{*}{ Arabidopsis thaliana } & GI3929585 & SCCCRZ2001E12.g & 178 & $2 \mathrm{E}-045$ \\
\hline & & SCEPAM2013E03.g & 131 & $1 \mathrm{E}-030$ \\
\hline \multicolumn{5}{|l|}{ NPH3 } \\
\hline \multirow[t]{2}{*}{ Arabidopsis thaliana } & GI6224711 & SCQSST1038C03.g & 381 & $1 \mathrm{E}-105$ \\
\hline & & SCEQAD1018D12.g & 326 & $3 \mathrm{E}-89$ \\
\hline \multicolumn{5}{|l|}{ CCA1 } \\
\hline \multirow[t]{3}{*}{ Arabidopsis thaliana } & & SCCCLR1048E10.g & 134 & $2 \mathrm{E}-31$ \\
\hline & GI15226444 & SCEZSB1093G09.g & 100 & $1 \mathrm{E}-20$ \\
\hline & & SCEQRT2027F03.g & 105 & $3 \mathrm{E}-22$ \\
\hline \multicolumn{5}{|l|}{ COP1 } \\
\hline Oryza sativa subsp. indica & GI13925701 & SCCCCL6003C08.g & 618 & $1 \mathrm{E}-176$ \\
\hline Oryza sativa subsp. indica & GI13925701 & SCJFRZ2013A10.g & 200 & $2 \mathrm{E}-50$ \\
\hline \multicolumn{5}{|l|}{ GIGANTEA } \\
\hline Oryza sativa & GI5912299 & SCCCRZ1001A06.g & 1390 & 0.0 \\
\hline Arabidopsis thaliana & GI6002520 & SCCCRZ3001B05.g & 225 & $4 \mathrm{E}-58$ \\
\hline Arabidopsis thaliana & GI17433083 & SCVPRT2079D03.g & 281 & $1 \mathrm{E}-74$ \\
\hline \multicolumn{5}{|l|}{ SUB1 } \\
\hline Arabidopsis thaliana & AL161512 & SCCCLR2001G03.g & 529 & $1 \mathrm{E}-149$ \\
\hline
\end{tabular}

\section{DISCUSSION}

The sequencing of the genome of the weed Arabidopsis thaliana during the Arabidopsis Genome Initiative reveal novel information about genomic organization, plant physiology and evolutionary relationships. One aspect with implications for some general conserved mechanisms be- tween plants was the high degree of gene redundancy for several proteins of known and unknown function.

This peculiar aspect of the Arabidopsis genome seems to be represented in the small family of phytochromes (A to E) known to be present in this plant. Mutant forms of phyA and phyB are frequent (see the review by 


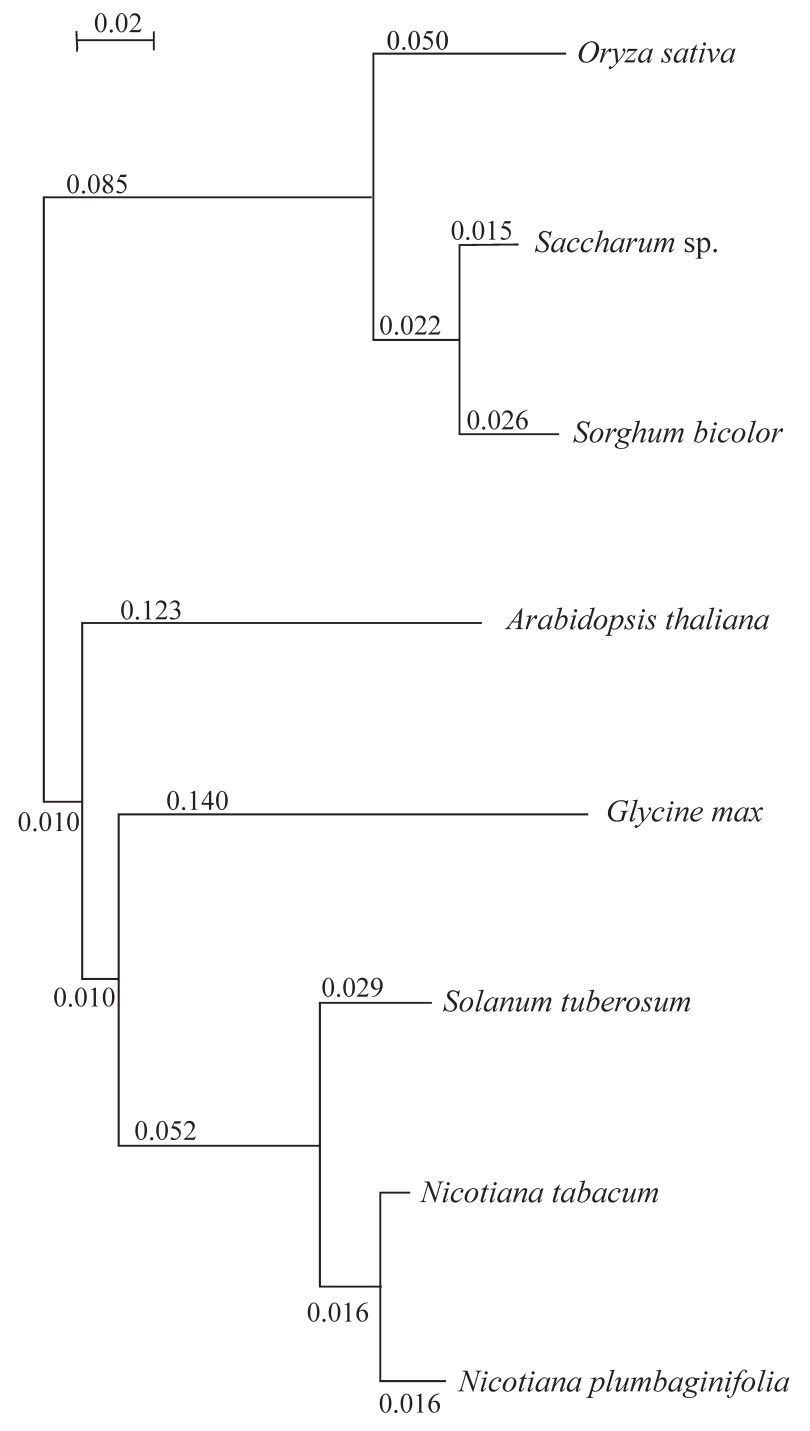

Figure 2 - Partial phylogenetic comparisons between the $P H Y B$ sequence from Saccharum $s p$ and complete $P H Y B$ sequences available for other plants.

Hudson, 2000), but phyC and phy E mutants remain elusive. Only one natural null mutant of phy D has been observed which indicates a minor role for this phytochrome. Why then are phyD and phyE maintained if most of their functions are noticeable only in a phyA/phyB double-mutant background? Hudson has suggested that "the redundancy that they provide may be the key for their retention, rather than any specific response for which they are required in wild type Arabidopsis".

We are able to detect phyA, phyB and phyC homologues in the SUCEST database. This is the same situation observed in rice. In this monocotyledon it was possible to demonstrate that the PHYA, PHYB and PHYC genes are all located on chromosome 3 , and of conserved synteny with these same genes in linkage group C from Sorghum (Basu et al., 2000).
This redundancy or high gene density seems to be a recurrent model in small and large grass genomes (wheat, barley and rice) as is the case for the Lrk genes that encode receptor-like kinases (Feuillet and Keller, 1999).

The present identification (by sequence homology) of at least three members of the phytochrome family in sugarcane, as well as homologues to cryptochromes and phototropin will open the possibility of interesting comparisons at a genomic level to other monocotyledons. In this sense it is noteworthy that, as observed for maize, no NPL1 (phototropin homologue) was found in the SUCEST database.

With the exception of PKS1, not found in the SUCEST database we found homologues to genes being postulated to act in the primary photoreceptor response, mainly PIF3. However in the case of NDPK2, several other putative sequences for NDPKs were present which may suggest a more general role for this protein. Because of this, this element was not included in our table. In this context the conclusive presence of a PIF3 homologue reinforces the possible implication of this protein in primary phytochrome signaling in plants.

The situation is also very interesting for other members described previously as important elements in photo-transduction. High scores were found for CCA1 and GIGANTEA, with Table I giving a complete list of elements. The FHY1 protein, a recent identified phytochrome A-specific signal transducer was not found (Desnos et al. 2001).

Although incomplete, the dendrogram showed in Figure 2 aligned Saccharum with Sorghum bicolor but distant from Oryza sativa. The sequence available from Zea mays is incomplete and in a region not comparable to that from Saccharum. The information for maize is limited and we suggest that the completion of the phytochrome B sequence from either sugarcane or maize will furnish interesting phylogenetic relationships in relation to the position of these plants in the grass family (Mattews et al., 2000).

Our studies have revealed basic evolutionary information and open the opportunity to apply to sugarcane the same approach that revealed essential information about light transduction signaling in other plants. Taken together, these results contribute valuable information to what is known about light transduction signaling in monocotyledons.

\section{RESUMO}

A partir dos dados do projeto de sequenciamento de Ests da Cana de Açúcar (Sucest/FAPESP) e utilizando BLAST (tblastn) como ferramenta, foi realizada uma busca de genes homólogos aos elementos envolvidos nos processos de foto-recepção e já descritos para outras plantas, principalmente Arabidopsis. Foram obtidas altas identidades para os fitocromos A, B e C assim como para os criptocromos 1,2 e a fototropina. Diversos elementos identificados como reguladores primários ou secundários na 
transdução de sinal de foto-receptores também foram identificados com baixos valores de E-value.

\section{ACKNOWLEDGEMENTS}

We thank FAPESP for the support of the Sucest project and to Dr. Brian Bandy for valuable suggestions. F. Siviero is a doctoral student with support from CAPES.

\section{REFERENCES}

Basu D, Dehesh K., Schneider-Poetsch H.J., Harrington S.E., McCounch, S.R., and Quail P.H. (2000). Rice PHYC gene: structure, expression, map position and evolution. Plant Mol. Biol. 44 (1): 27-42.

Chantao, L. (2000). Plant blue-light receptors. Trends in Plant Sciences 5: 337-342.

Choi, G., Yi H., Lee, J. Kuon, Y.K., Soh, M.S., Shin, B.. Luka, Z., Hahn, T.R. and Song P.S. (1999). Phytochrome signalling is mediated through nucleotide diphosphate kinase 2 . Nature 401: 610-613.

Christie, J.M., Reymond, P., Powell, G.K., Bernasconi, P., Raibekas, A.A.,Liscum, E. and Briggs W.R. (1998) Arabidopsis NPH1: a flavoprotein with the properties of a photoreceptor for phototropism. Science 282: 1698-1701.

Desnos, T., Puente, P., Whitelam, G.C. and Harberd, N.P. (2001) FHY1: a phytochrome A-specific signal transducer. Genes \& Dev. 15: 2980-2990.

Fairchild, C.D., Schumaker, M.A., and Quail, P.H., (2000). HFR1 encodes an atypical bHLH protein that acts in phytochrome A signal tranduction. Genes \& Development 14: 2377-2391.

Fankhauser, C., Yeh, K.C., Lagarias, J.C., Zhang, Elich, T.D. and Chory, J. (1999). PKS1, a substrate phosphorylated by phytochrome that modulates light signalling in Arabidopsis. Science 284: 1539-1541.

Feuillet, C., Keller, B. (1999). High gene density is conserved at syntenic loci of small and large grass genomes. Proc. Natl. Acad. Sci U.S.A. 96: 8265-8270.

Guo, H., Mockler, T., Duong, C. and Lin, C. (2001). SUB1, an Arabidopsis $\mathrm{Ca}^{2+}$ Binding Protein Involved in Cryptochrome and Phytochrome Coaction. Science 291: 487-490.

Huq E., Tepperman, J.M. and Quail, P.H. (2000) GIGANTEA is a nuclear protein involved in phytochrome signaling in Arabidopsis. Proc. Natl. Acad. Sci. USA 97 (17): 9789-9794.

Hudson, M.E. (2000) The genetics of phytochrome signalling in Arabidopsis . Semin Cell \& Dev Biol. 11: 475-483.

Jarillo, J.A., Gabrys, H., Capel, J., Alonso, J.M., Ecker, J.R. and Cashmore, A.R. (2001). Phototropin-related NPL1 controls chloroplast relocation induced by blue light. Nature 410: 952-954.

Kagawa, T.,Sakai, T., Suetsugu, N., Oikawa, S. Kato, T., Tabata, S, Okada, K, Wada, M. (2001) Arabidopsis
NPL1: a phototropin homolog controlling the chloroplast high-light avoidance response. Science 291: 2138-2140.

Liscum, E., Stowe-Evans, E.L. (2000). Phototropism: a "simple" physiological response modulated by multiple interacting photosensory-response pathways. Photochem Photobiol 72 (3): 273-282.

Martinez-Garcia, J.F., Huq, E. and Quail, P.H. (2000). Direct targeting of light signals to a promoter element-bound transcription factor. Science 288 (5467): 859-63.

Mattews, S., Tsai, R. and Kellogg, E.A. (2000). Phylogenetic structure in the grass family (POACEAE): evidence from the nuclear gene Phytochrome B. Am. Jour. Bot. 87 (1): 96-107.

McNellis, T.W., Torii, K.U. and Deng, X.W. (1994). Over-expression of Arabidopsis COP1 results in partial suppression of light mediated development and evidence for a light inactivable suppressor of photomorphogenesis. Plant Cells 6: 1391-1400

Moutchoulski, A. and Liscum, E (1999). Arabidopsis NPH3: A NPH1 Photoreceptor-interacing protein essential for phototropism. Science 286: 961-964.

Nagy, F., Kircher, S. and Schäfer, E., (2000). Nucleo-cytoplasmic partitioning of the plant photoreceptors phytochromes. Semin Cell \& Dev Biol. 11: 505-510.

Nagy, F., Kircher, S., and Schäfer, E. (2001). Intracellular trafficking of photoreceptors during light-induced signal transduction in plants. J. Cell Sci. 114: 475-480.

Ni, M., Tepperman, J.M. and Quail, P.H. (1999). Binding of phytochrome B to its nuclear signaling partner PIF3 is reversibly induced by light. Nature 19 (400): 781-784.

Quail, P.H., (2000). Phytochrome-interacting factors. Semin Cell \& Dev Biol. 11: 457-466.

Smith, H. (1999). Tripping the light fantastic. Nature 19 (400): $710-711$.

Thompson JD, Gibson TJ, Plewniak F, Jeanmougin F, Higgins DG. (1997). The CLUSTAL_X windows interface: flexible strategies for multiple sequence alignment aided by quality analysis tools. Nucleic Acids Res Dec 15; 25 (24): 4876-82.

Yang, H.Q., Tang, R.H. and Cashmore, A.R. (2001) The signaling Mechanism of Arabidopsis CRY1 involves direct interaction with COP1. Plant Cell 13: 2573-2587.

Zhu, Y., Tepperman, J.M., Fairchild, C.D., Quail, P.H. (2000). Phytochrome B binds with greater apparent affinity than phytochrome A to the basic helix-loop-helix factor PIF3 in a reaction requiring the PAS domain of PIF3. Proc. Natl. Acad. Sci, USA 97: 13419-13424.

Wang, Z.Y. and Tobin, E.M. (1998). Constitutive expression of the CYRCADIAN CLOCK ASSOCIATED 1 (CCA1) gene disrupts circadian rhythms and suppresses its own expression Cell 93: 12:07-1217. 